\title{
Non-metastatik mide kanserli olgularda prognostik faktörler
}

\author{
Prognostic factors in patients with non-metastatic gastric cancer \\ Turgut Kaçan*, Nalan Akgün Babacan, Saadettin Kılıçkap, Mehmet Metin Şeker, \\ Birsen Yücel, Tunahan Uncu, Ali Yılmaz
}

Tıbbi Onkoloji Bilim Dalı (Dr. T. Kaçan, Yrd. Doç. Dr. N. A. Babacan, Doç. Dr. S. Kılıçkap, Yrd. Doç. Dr. M. M. Şeker), Radyasyon Onkolojisi Anabilim Dalı (Yrd. Doç. Dr. B. Yücel), İç Hastalıkları Anabilim Dalı (Dr. T. Uncu, Dr. A. Yılmaz) Cumhuriyet Üniversitesi Tıp Fakültesi, TR-58140 Sivas

\begin{abstract}
Özet
Amaç. Mide kanseri kansere bağlı ölümlerin en s1k nedenlerinden biridir. Prognostik faktörler tedavi kararını etkileyebilir. Bu retrospektif çalışmada merkezimizde takip edilen non-metastatik mide kanseri olgularda prognostik faktörlerin belirlenmesi amaçlandı. Yöntem. Hasta verileri hasta dosyası ve hastane kayıtlarından elde edildi. Demografik veriler ve patolojik bulgular toplanarak veri tabanına kaydedildi. Tümör ve hastaya ait prognostik faktörlerin yanı sıra, laboratuvar parametreleri incelendi. Bulgular. Çalışmada 2009-2011 tarihleri arasında bölümümüze başvuran mide kanseri tanısı almış 120 hastanın verileri analiz edildi. Olguların yaş

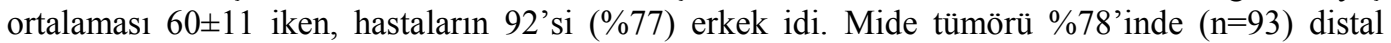
yerleşimli idi. En sık görülen evre $\% 71$ ile evre 3 idi. Tüm olguların \%62'sinde lenfovasküler invazyon pozitif idi. Olguların \%44’ü kötü diferansiye tümör idi. En sık ECOG performans skoru “0” (\%64) görüldü. Ortanca tümör çapı $5 \mathrm{~cm}$ (1-15) idi. Ortanca çıkarılan lenf nodu sayısı 20 (254) iken, ortanca tutulmuş lenf nodu sayısı 5 (0-44) idi. Yüzde seksen hastada lenf nodu tutulumu mevcuttu. Ortanca izlem süresi 22 ay idi. Üç yıllık sağkalım oranları evre arttıkça azalmaktaydı. CEA yüksekliği, evre, lenf nodu tutulumu, performans skoru, ekstralenfatik yayılım ve anemi sağkalımı etkileyen faktörler idi. CEA yüksekliği ve evre sağkalımı etkileyen bağımsız değişkenlerdi. Sonuç. Non-metastatik mide kanserinde evre ve CEA yüksekliği sağkalımı bağımsız olarak etkilemektedir.
\end{abstract}

Anahtar sözcükler: Non-metastatik mide kanseri, CEA, prognostik faktörler

\begin{abstract}
Aim. Gastric cancer is one of the leading causes of cancer-related deaths. The prognostic factors may affect decision of the treatment. In this retrospective study, we aimed to determine prognostic factors for non-metastatic gastric cancer in patients who were followed-up in our centre. Method The data were obtained from patients' file and the hospital records. The demographic parameters and pathological findings of the patients were recorded at the database. In addition to the laboratory tests of all patients, tumor,- and patient-related prognostic factors were also evaluated. Result. Data of 120 patients with gastric cancer at followed-up in our department between 2009 and 2011 were analyzed in this study. The mean age of the patients was $60 \pm 11$, and $92(77 \%)$ were male. Seventy-eight percent of gastric cancer $(n=93)$ were localized in the distal. The most common occurred stage was stage $3(71 \%)$. Of patients, lymphovascular invasion was $62 \%$ and $44 \%$ had poorly differentiated tumor. The most common performance status was ECOG " 0 " (64\%). The median tumor size was $5 \mathrm{~cm}(1-15 \mathrm{~cm})$. The number of median excised lymph node was 20 (2-54) and the median involved lymph node was 5 (0-44). Eighty percent of patients were lymph node positive. The median follow-up period was 22 months. The 3 -year survival rates were decreasing according to stage. CEA elevation, stage, node involvement, performance status, extralymphatic extension, and anemia were prognostic factor for survival. CEA and the stage of disease were independently prognostic factors for survival. Conclusion. Stage and higher CEA independently affect survival in non-metastatic gastric cancer.
\end{abstract}

Keywords: Non-metastatic gastric cancer, CEA, prognostic factors 
Geliş tarihi/Received: 26 Aralık 2012; Kabul tarihi/Accepted: 10 Temmuz 2013

\author{
*İletişim adresi: \\ Dr. Turgut Kaçan, Onkoloji Anabilim Dalı, Cumhuriyet Üniversitesi Tıp Fakültesi, TR-58140 \\ Sivas. E-mail: kacanturgut@gmail.com
}

\title{
Giriş
}

Kanser tüm dünyada kardiyovasküler hastalıklardan sonra en sık görülen ve en sık ölüme sebep olan ikinci hastalıktır [1]. Kanserli hastalarda kanserin kendisi veya kanser tedavisine ikincil ortaya çıkan morbid durumlar nedeniyle de önemli sağlık sorunları ortaya çıkabilmektedir.

Mide kanseri ülkemizde ikinci siklıkta görülen kanserlerdir [2, 3]. Ancak agresif tümörlerden biri olması nedeniyle hastaların çoğu genellikle ileri evrede tanı almaktadır. Mide kanserinde prognoz ile ilgili yapılmış çalışmalarda tümör ilişkili (lenf nodu metastazı, lokalizasyonu, perinöral ve damar invazyonu, tümör evresi ve büyüklüğü, uzak metastaz, histolojik ve diferansiyasyon derecesi) ve tedavi ilişkili (cerrahi tipi, lenfadenoktemi) faktörler tanımlanmıştır [4]. Bununla birlikte laboratuvar parametreleri de (hemoglobin, karsinoembriyojenik antijen gibi) prognozu belirlemekte kullanılmakla birlikte, ideal prognostik belirteçlerin arayışı halen devam etmektedir.

$\mathrm{Bu}$ çalışmada merkezimizde takip edilen non-metastatik mide kanseri olgular retrospektif olarak incelenerek prognostik faktörlerin değerlendirilmesi amaçlandı.

\section{Gereç ve yöntem}

Bu çalışmada Cumhuriyet Üniversitesi Onkoloji Merkezi’nde takip ve tedavi edilen mide kanserli hastalarda prognostik faktörler ve sağkalım arasındaki ilişki irdelenmeye çalışıldı. Bu nedenle hasta dosyaları ve hastane kayıtları retrospektif olarak incelendi. Hastalara ait yaş ve cinsiyet gibi demografik verilerin yanı sıra, tümörün lokalizasyonu, çapı, lenfovasküler invazyon (LVI), lenf nodu tutulumu, diferansiasyonu, metastaz varlığı ve evre gibi hastalık ilişkili faktörler kaydedildi. Hastaların performans durumu Eastern Cooperative Oncology Group performans skoru (ECOG PS) ile değerlendirildi. Hastalara ait tanı anındaki tam kan sayımı, total biyokimya, karsinoembriyojenik antijen (CEA) ve karbohidrat antijen 19-9 (Ca 19-9) gibi tümör belirleyicilerinin değerleri kaydedildi. Çalışmaya histopatolojik olarak mide adenokanser tanısı almış hastalar dahil edildi. Akciğer ve karaciğer gibi uzak metastazı olan, yaygın peritoneal metastazı olan, cerrahi sonrası patoloji sonuçlarına ulaşılamayan ve adenokanser histolojisi olmayan hastalar çalışma dışında bırakıldı.

\section{Ístatistiksel analiz}

Tüm veriler SPSS 15,0 veri tabanına yüklendi. Sıklık tablosu yanı sıra, veriler ki-kare testi, Mann-Whitney U testi kullanılarak analiz edildi. Sağkalım analizi için KaplanMeier yöntemi kullanıld1. Tüm veriler çift yönlü olarak değerlendirildi ve $\mathrm{p}<0,05$ düzeyi anlamlı olarak kabul edildi.

\section{Bulgular}

Çalışmada 2009-2011 tarihleri arasında bölümümüze başvuran verileri yeterli olan mide kanseri tanısı almış toplam 120 hastanın verileri analiz edildi. Hasta karakteristikleri Tablo 1'de özetlendi. Çalışmaya alınan hastaların yaş ortalaması $60 \pm 11$ idi. Hastaların 28'i (\%23) kadın, 92'si (\%77) erkek idi. Olguların \%78'inde (n=93) mide tümörü distal yerleşimli iken, \%22'sinde $(\mathrm{n}=27)$ proksimal yerleşimli idi.

Hastaların \%73'üne $(n=87)$ total gastrektomi, \%23'üne de $(n=28)$ subtotal gastrektomi, \%4'üne ise $(n=5)$ sadece biopsi yapılmıştır. Hastaların tümüne lenf nodu disseksiyonu yapılmış ancak cerrahi tedavilerin aynı merkezde yapılmaması nedeniyle lenf nodu disseksiyonunun tipi birçok hasta için belirlenememiştir. Ortanca lenf nodu disseksiyonu 
20 (2-54) olarak belirlendi. Cerrahi tedavi yapılan 115 hastanın \%85'inde ( $\mathrm{n}=102)$ cerrahi sınır negatif iken, \%11'inde ( $\mathrm{n}=13)$ cerrahi sınır pozitifliği bulunmaktaydı.

En s1k görülen evre \%71 ile Evre 3 (\%37'si 3C) idi. Histopatolojik olarak vakaların $\% 44$ 'ü kötü diferansiye, \%80'inde nod pozitif ve \%62 hastada LVI pozitifti. Ortanca tümör çap1 $5 \mathrm{~cm}$ (1-15), çıkarılan lenf nodu sayısı 20 (2-54) ve ortanca tutulmuş lenf nodu sayıs 5 (0-44) bulundu. Hastaların ECOG PS sirasiyla: ECOG 0, \%64, ECOG I \%29 ECOG $>1 \% 7$ idi. Ortanca izlem süresi 22 ay idi. Üç yıllık sağkalım oranları Evre I için $\% 83$, Evre II için \%78 ve Evre III için \%41 idi.

Tek değişkenli analizde CEA yüksekliği $(\mathrm{p}=0,004)$, evre $(\mathrm{p}=0,024)$, lenf nodu tutulumu $(p=0,030)$, ECOG performans skoru $(p=0,050)$, ekstralenfatik yayllım $(p=0,031)$ ve anemi $(\mathrm{p}=0,050)$ sağkalımı etkileyen faktörler idi (Tablo 2). Çok değişkenli analizde ise CEA yüksekliği $(\mathrm{p}=0,006)$ ve evre $(\mathrm{p}=0,044)$ sağkalımı etkileyen bağımsız değişkenlerdi.

Tablo 1. Hasta karakteristikleri.

\begin{tabular}{|c|c|c|c|c|}
\hline & & Ortanca (Min-Max) & $\mathbf{n}$ & $\%$ \\
\hline Yaş (ort \pm ss, yıl) & & $60 \pm 11$ & & \\
\hline Çap (ortanca, cm) & & $5(1-15)$ & & \\
\hline Çıkarılan lenf nodu & & $20(2-54)$ & & \\
\hline Tutulmuş lenf nodu & & $5(0-44)$ & & \\
\hline \multirow{2}{*}{ Cinsiyet } & Kadın & & 28 & 23 \\
\hline & Erkek & & 92 & 77 \\
\hline \multirow{2}{*}{ Yerleşim } & Proksimal & & 27 & 22 \\
\hline & Distal & & 93 & 78 \\
\hline \multirow{3}{*}{ Diferansiasyon } & İyi & & 19 & 17 \\
\hline & Orta & & 41 & 36 \\
\hline & Kötü & & 54 & 47 \\
\hline \multirow{2}{*}{ LVI } & Yok & & 46 & 38 \\
\hline & Var & & 74 & 62 \\
\hline \multirow{3}{*}{ ECOG } & 0 & & 77 & 64 \\
\hline & 1 & & 35 & 29 \\
\hline & $>1$ & & 8 & 7 \\
\hline \multirow{2}{*}{ Nod } & Negatif & & 25 & 20 \\
\hline & Pozitif & & 95 & 80 \\
\hline \multirow{3}{*}{ Evre } & I & & 8 & 7 \\
\hline & II & & 26 & 22 \\
\hline & III & & 86 & 71 \\
\hline
\end{tabular}

Tablo 2. Sağkalım ve etkileyen faktörler.

\begin{tabular}{llc}
\hline & & $\mathbf{\%}$ \\
\hline Ortanca izlem süresi & 22 ay \\
& Evre I & 83 \\
3-yıllık sağkalım & Evre II & 78 \\
& Evre III & 41 \\
\hline Tek değişkenli analiz & & \\
\hline CEA (normal vs yüksek) & & 0,004 \\
Evre (1 vs 2 vs 3) & & 0,024 \\
Nod (negatif vs pozitif) & 0,030 \\
ECOG PS (0 vs 1 vs 2) & 0,050 \\
Ekstralenfatik yayılım (yok vs var) & & 0,031 \\
Anemi (yok vs var) & & 0,050 \\
\hline Çok değişkenli analiz & \\
\hline CEA & & 0,006 \\
Evre & & 0,044 \\
\hline
\end{tabular}




\section{Tartışma}

Kanser hastalığı, dünyada ve Türkiye'de önemli bir halk sağlığı sorunudur. Türkiye'de 2000 yılında toplam 67 bin kişinin kansere yakalandığı ve bu kişilerin 47 bininin hayatını kaybettiği bildirilmiştir [5]. Dünya Sağlık Örgütü verilerine göre 2020 y1lında kanser tanısı konulan hasta sayısının 17 milyona, şu andaki oranlarda bir değişiklik olmadığı takdirde 2030 yılında kanser tanısı konulan hasta sayısının 20 milyona ulaşabileceği öngörülmektedir [6].

Mevcut en son tahminlere göre mide kanseri dünya genelinde en yaygın dördüncü kanser türüdür ve yılda 934000 vaka ortaya çıkmaktadır [5]. Kansere bağlı ölümler arasında önemli bir yere sahiptir. Bu nedenle mide kanserinde sağkalımı etkileyen faktörlerin tespiti son derece önemlidir.

Hastalığın prognozunu belirleyen faktörler, hastaya, tümöre ve tedaviye ait olabilir. TNM evresi, mide kanserinde en önemli prognostik faktördür. Ancak aynı evrede olmasına rağmen hastaların prognozunda farklılık olabileceği için başka prognostik faktörler de kullanmak gerekebilmektedir [4, 6].

Yapılan sağkalım analiz çalışmalarında ileri yaşın yanı sıra tümör evresinin ileri olmasının mide kanserli hastalarda prognozunun kötü olduğunu ortaya koymuştur [7]. Hasta yaşının mide kanserli hastalarda önemli bir prognostik faktör olduğu yapılan çalışmalarda gösterilmiştir. Yaşlı hastalarda zayıf immünite, malnutrisyon ve saptanamayan mikrometastazlar nedeniyle sağkalımın kısa olduğu bildirilmiştir [8]. Ancak yaş ile sağkalım arasında ilişkinin olmadığını gösteren yayınlarda bulunmaktadır [9]. Bizim çalışmamızda hastaların ve ileri evrenin sağkalımı azalttı̆ğ gösterilmiş iken yaş ile sağkalım arasında anlamlı bir ilişki bulunamadı.

Mide kanserleri için lenf nodu tutulumu ve yayılım paterni çok önemli bir prognostik faktördür $[10,11]$. Japonya ve diğer ülkelerde yapılan randomize olmayan çalışmalarda, artmış lenf nodu tutulumunun ( $\geq \% 20$ ) kötü prognostik faktör olduğu, bu nedenle genişletilmiş lenf nod rezeksiyonu ile çıkartılan metastatik lenf nodu sayısının artacağı ve bu sayede sağkalımın artırılabileceği vurgulanmıştır [12, 13]. Çalışmamızda hastaların \%80'inde lenf nodunda pozitiflik saptandığı, çıkarılan ortanca lenf nodu sayısının 20 (2$50)$, tutulan lenf nodu sayısının ortanca 5 (0-44) olduğunu saptadık. Çalışmamız literatürdekine benzer şekilde nod pozitifliğinin sağkalımı etkilediğini göstermiştir.

Lenf nodu tutulumunun yanısıra ekstralenfatik yayılımın da sağkalımda etkili olduğu bilinmektedir [14]. Perinöral invazyon ve damar invazyonu, uzak metastaz varlı̆̆ sağkalım üzerine önemli etkisi olması nedeniyle önemli bir prognostik faktördür $[15,16]$. Çalışmamızda da ekstralenfatik yayılımın sağkalımı etkileyen bir faktör olduğu gösterilmiştir.

Tümör belirteçleri, tanı, tedaviye cevabı değerlendirme, izleme ve nüksleri saptamada kullanılmaktadır. Mide kanserinde CEA düzeyi normal olan hastaların sağkalımı CEA düzeyi yüksek olan hastalara göre daha iyidir [17]. Bizim yaptığımız çalışmada da yüksek CEA düzeyi kötü sağkalımla ilişkili bulunmuştur. Ayrıca nutrisyonel destek eksikliği ve aneminin derecesi ile mide kanseri sağkalımı arasında korelasyonun olduğunu bildiren çalışmalar da mevcuttur [18]. Kendi hasta grubumuzda da derin anemisi olan hastaların benzer şekilde sağkalımının daha kötü olduğu gösterilmiştir.

Mide kanserli hastalarda Eastern Cooperative Oncology Group (ECOG) performans durumu 0-1 olan hastaların prognozlarının performans durumu 2 veya daha yukarı olan hastalara göre daha iyidir. Tedavi planı yapılırken hastaların performans durumları prognozu etkilediğinden için dikkatle değerlendirilmelidir [19]. Bizim çalışmamızda ECOG performans durumu 0-1 olan hastaların oran $\% 93$ idi. ECOG performans durumu $>1$ olanlara göre daha iyi sağkalıma sahiptiler. Kendi hasta grubumuzda da benzer şekilde sağkalım ile arasında istatiksel olarak anlamlı ilişki mevcuttu. 
Distal mide kanseri oranı proksimal mide kanserine oranla daha fazla izlenmektedir. Proksimal mide kanserinin distal mide kanserinin biyolojik davranışından farklı olduğu göz önüne alınarak yapılan çalışmalarda aralarında prognostik açıdan bir fark olmadığı gösterilmiştir [20, 21]. Bizim çalışmamızda da distal mide kanseri oranı daha fazla idi ve sağkalım ile arasında ilişki yoktu.

Son dönemde yapılan çalışmalarda tümör çapı ve tümör diferansiasyonunun prognostik faktörler olarak gösterilmesi gerektiği gösterilmiştir. Kötü diferansiye , tümör çap $7 \mathrm{~cm}$ ve üzeri olan hastaların prognozunun daha kötü olduğu bildirilmiştir [22]. Çalışmamızda tümör çap1 $1 \mathrm{~cm}$ ile $15 \mathrm{~cm}$ arasında değişmekte olup ortanca $5 \mathrm{~cm}$ idi. Kötü diferansiye mide tümörleri \%47 idi. Literatürdekinin aksine prognozla arasında ilişki saptanamadı.

Çalışmamızın bazı sınırlılıkları bulunmaktadır. Öncelikle çok değişkenli analiz için çalışmamızdaki hasta sayısı sınırlıdır. Ancak analiz sonuçları analiz edilen değişken sayısı dikkate alındığında göz ardı edilebilir. Bir diğer kısıtlılık ise hasta izlem süresinin nispeten kisa olmasidır.

Sonuç olarak non-metastatik mide kanserinde çok sayıda prognostik faktörden bahsetmek mümkündür. Çalışmamızda tümör evresi ve CEA yüksekliği sağkalımı belirleyen bağımsız prognostik faktörler olarak bulunmuştur. Ancak daha geniş sayıda hasta katılımının sağlandığı çalışmalarla prognostik faktörlerin belirlenmesi yararlı olabilir.

Cerrahi tedavi uygulanan hastaların aynı merkezde yapılmaması ve bu nedenle de disseksiyon tipinin belirlenememesi, çalışmanın retrospektif olması, hasta sayısının az olması bu çalışma için sınırlayıcı faktörler olmuştur.

\section{Kaynaklar}

1. World Health Organization. The Global Burden of Disease: 2004 Update. Geneva: World Health Organization 2008.

2. Eser S, Yakut C, Özdemir R, Karakilinç H, Özalan S, Marshall SF, Karaoğlanoğlu O, Anbarcioğlu Z, Üçüncü N, Akin Ü, Özen E, Özgül N, AntonCulver H, Tuncer M. Cancer incidence rates in Turkey in 2006: A detailed registry based estimation. Asian Pac J Cancer Prev 2010; 11: 1731-9.

3. Kılıçkap S, Tapan Ü, Yalçın Ş. Metastasis to bone from gastric cancer: a single centre experience. Cumhuriyet Med J 2010; 32: 192-8.

4. Sánchez-Bueno F, Garcia-Marcilla JA, Perez-Flores D, Pérez-Abad JM, Vicente R, Aranda F, Ramirez P, Parrilla P. Prognostic factors in a series of 297 patients with gastric adenocarcinoma undergoing surgical resection. Br J Surg 1998; 85: 255-60.

5. Ferlay J, Shin HR, Bray F, Forman D, Mathers C, Parkin DM. Estimates of worldwide burden of cancer in 2008: GLOBOCAN 2008. Int J Cancer 2010; 15; 127: 2893-917.

6. Hartgrink HH, van de Velde CJ, Putter H, Bonenkamp JJ, Klein Kranenbarg E, Songun I, Welvaart K, van Krieken JH, Meijer S, Plukker JT, van Elk PJ, Obertop H, Gouma DJ, van Lanschot JJ, Taat CW, de Graaf PW, von Meyenfeldt MF, Tilanus H, Sasako M. Extended lymph node dissection for gastric cancer: who may benefit? Final results of the randomized Dutch gastric cancer group trial. J Clin Oncol 2004; 1; 22: 2069-77.

7. Pacelli F, Papa V, Caprino P, Sgadari A, Bossola M, Doglietto GB. Proximal compared with distal gastric cancer: multivariate analysis of prognostic factors. Am Surg 2001; 67: 697-703.

8. Baba H, Maehara Y, Takeuchi H, Inutsuka S, Okuyama T, Adachi Y, Akazawa $\mathrm{K}$, Sugimachi K. Effect of lymph node dissection on the prognosis in patients with node-negative early gastric cancer. Surgery 1995; 117: 165-9.

9. Adachi Y, Ogawa Y, Sasaki Y, Yukaya H, Mori M, Sugimachi K. A clinicopathologic study of gastric carcinoma with reference to age of patients. J Clin Gastroenterol 1994; 18: 287-90. 
10. Sasako M, McCulloch P, Kinoshita T, Maruyama K. New method to evaluate the therapeutic value of lymph node dissection for gastric cancer. Br J Surg 1995; 82: 346-51.

11. Kitamura K, Yamaguchi T, Taniguchi H, Hagiwara A, Sawai K, Takahashi T. Analysis of lymph node metastasis in early gastric cancer: rationale of limited surgery. J Surg Oncol 1997; 64: 42-7.

12. Maehara Y, Kakeji Y, Koga T, Emi Y, Baba H, Akazawa K, Sugimachi K. Therapeutic value of lymph node dissection and the clinical outcome for patients with gastric cancer. Surgery 2002; 131: S85-91.

13. Siewert JR, Böttcher K, Stein HJ, Roder JD. Relevant prognostic factors in gastric cancer: ten-year results of the German Gastric Cancer Study. Ann Surg 1998; 228: 449-61.

14. Adachi Y, Shiraishi N, Suematsu T, Shiromizu A, Yamaguchi K, Kitano S. Most important lymph node information in gastric cancer: multivariate prognostic study. Ann Surg Oncol 2000; 7: 503-7.

15. Duraker N, Sişman S, Can G.The significance of perineural invasion as a prognostic factor in patients with gastric carcinoma. Surg Today 2003; 33: 95100.

16. Scartozzi M, Galizia E, Verdecchia L, Berardi R, Graziano F, Catalano V, Giordani P, Mari D, Silva RR, Marmorale C, Zingaretti C, Cascinu S. Lymphatic, blood vessel and perineural invasion identifies early-stage high-risk radically resected gastric cancer patients. Br J Cancer 2006; 95: 445-9.

17. Mihmanli M, Dilege E, Demir U, Coskun H, Eroglu T, Uysalol MD. The use of tumor markers as predictors of prognosis in gastric cancer. Hepatogastroenterology 2004; 51: 1544-7.

18. Shen JG, Cheong JH, Hyung WJ, Kim J, Choi SH, Noh SH. Pretreatment anemia is associated with poorer survival in patients with stage I and II gastric cancer. J Surg Oncol 2005; 91: 126-30.

19. .Kanagavel D, Pokataev IA, Fedyanin MY, Tryakin AA, Bazin IS, Narimanov MN, Yakovleva ES, Garin AM, Tjulandin SA. A prognostic model in patients treated for metastatic gastric cancer with second-line chemotherapy. Ann Oncol 2010; 21: 1779-85.

20. Navaneethan U, Beg MS, Komrokji R, Safa MM. Characteristics of proximal versus distal gastric cancer at the VA: Is there a difference? J Clin Oncol (Meeting Abstracts) 2008; 26: suppl 15517.

21. Piso P, Werner U, Lang H, Mirena P, Klempnauer J. Proximal versus distal gastric carcinoma--what are the differences? Ann Surg Oncol 2000; 7: 520-5.

22. Saito H, Kuroda H, Matsunaga T, Fukuda K, Tatebe S, Tsujitani S, Ikeguchi M. Prognostic indicators in node-negative advanced gastric cancer patients. J Surg Oncol 2010; 101: 622-5. 